\title{
Replica of Human Dentin Treated With Different Desensitizing Agents: A Methodological SEM Study In Vitro
}

\author{
Jose Carlos PEREIRA ${ }^{1}$ \\ Ana Christina Bonato Figueiredo MARTINELI ${ }^{1}$ \\ Ming S. TUNG ${ }^{2}$ \\ ${ }^{1}$ Dentistry, Endodontics and Dental Materials Department, Bauru School of Dentistry, University of Sao Paulo, \\ Bauru, SP, Brazil \\ ${ }^{2}$ American Dental Association Health Foundation, Paffenbarger Research Center, Polymers Division, \\ National Institute of Standards and Technology, Gaithersburg, MD, USA
}

\begin{abstract}
This is a preliminary study to determine a methodological sequence in vitro which may allow the reproduction of dentin for SEM analysis, after the use of different desensitizing agents. Dentin discs obtained from extracted human third molars were etched with 6\% citric acid, an artificial smear layer was created and the surface dentin discs were divided into four quadrants. Quadrants 2, 3 and 4 of each disc were conditioned with $6 \%$ citric acid. The desensitizing agents (Oxa-Gel ${ }^{\circledR}$, Gluma Desensitizer and an experimental agent) were applied to quadrants 3 and 4 . To evaluate the acid resistance of the treatment, quadrant 4 was etched again with $6 \%$ citric acid. An impression was then taken with Aquasil ULV. After a setting period of $6 \mathrm{~min}$, each disc was removed from the impression and stored in a moist-free environment for $24 \mathrm{~h}$ at $37^{\circ} \mathrm{C}$. After that time, a low-viscosity epoxy resin (Araltec GY $1109 \mathrm{BR}$ ) was poured into the impression and cured for $24 \mathrm{~h}$. All specimens were metal-coated for SEM analysis. Comparison of the photomicrographs of dentin discs with their respective impressions and resin replicas showed that this technique can reproduce the characteristics of the dentin surface treated with desensitizing agents.
\end{abstract}

Key words: dentin hypersensitivity, replica.

\section{INTRODUCTION}

The hydrodynamic theory is the most commonly accepted mechanism to explain dentin hypersensitivity. According to this theory, painful stimuli coming from the oral environment act on the surface of the exposed dentin and cause a rapid fluid movement inside the dentinal tubules. This movement stimulates mechanoreceptors at pulp periphery, leading to pain sensation (1). Therefore, the most appropriate treatment for dentin hypersensitivity seems to be the obliteration of the dentinal tubule orifices (2).

The agents that obliterate dentinal tubules may produce protein precipitation, crystal precipitation on or in dentinal tubules or conventional restorative tech- niques may seal the tubules. Potassium oxalate is a desensitizing agent that acts not only by obliterating the dentinal tubules, with the precipitation of calcium oxalate crystals on the surface and inside the dentinal tubules, but also by depolarization of nerve endings. Calcium chloride and potassium phosphate solutions have been tested in vitro $(3,4)$ and in vivo $(5)$, and may work similarly. Both approaches have shown very promising results in treating dentin hypersensitivity.

The use of resins and adhesives as desensitizing agents has been reported by many authors (6). These agents promote the occlusion of the dentinal tubules by resin tag formation and by a thin layer of polymerized resin at the surface, leading to a long-lasting desensibilization.

Correspondence: Prof. Jose Carlos Pereira, DDS, PhD, Departamento de Dentística, Endodontia e Materiais Dentários, Faculdade de Odontologia de Bauru, Universidade de Sao Paulo, Alameda Dr. Octavio Pinheiro Brizolla 9-75, Vila Universitária, 17043-101, Bauru, SP, Brasil. Tel: +55-14235-8214; +55-14-235-8223. Fax: +55-14-223-7720. E-mail: jcper@fob.usp.br 
Earlier studies have reported use of replicas in order to observe normal and hypersensitive patterns of dentin surface (7-10) as well as to assess the effect of the desensitizing agents on dentin substrate $(3,6)$. However, the photographic documentation of these studies has shown low reproducibility of the original dentin surface characteristics. Moreover, technical instructions for replication are generally incomplete, which makes it difficult to use this method in similar studies.

The present investigation reports a methodological sequence in vitro that allows the reproduction of fine details of dentin specimens for SEM analysis after the use of different desensitizing agents.

\section{MATERIAL AND METHODS}

Recently extracted caries-free human third molars were sectioned with a diamond disc (Isomet; Buehler Ltd., Lake Bluff, IL, USA) at low speed and under water irrigation. The crown of each tooth was sectioned transversely above the projection of the pulp horns and below the oclusal amelodentinal junction. Only one dentin disc, approximately $1 \mathrm{~mm}$ thick, was obtained from each tooth. A total of three discs were used. The discs were etched with $6 \%$ citric acid for 2 min and rinsed in distilled water. Wet silicon carbide 600-grit sandpaper was used for $5 \mathrm{~s}$ on the oclusal side of each disc to create a standard smear layer.

After creating the smear layer, two crossed scratches which set the limits preventing "spill-over" were made on the discs to divide the dentin surface into four quadrants. Quadrants 2, 3 and 4 of each disc were then conditioned with $6 \%$ citric acid for $2 \mathrm{~min}$ on both sides and rinsed in distilled water in order to expose the dentinal tubules and simulate hypersensitive dentin,

Table 1. Desensitizing agents used.

\begin{tabular}{lll}
\hline Agents & Composition & Manufacturer \\
\hline Oxa-Gel $^{\circledR}(\mathrm{OG})$ & $\begin{array}{l}\text { 3\% Monopotassium oxalate } \\
\text { carboxymethylcellulose }\end{array}$ & $\begin{array}{l}\text { Art-Dent Indústria e Comércio Ltda. } \\
\text { São Paulo, SP, Brazil }\end{array}$ \\
$\begin{array}{lll}\text { Gluma Desensitizer } \\
(\mathrm{GD})\end{array}$ & $\begin{array}{l}36 \% \text { HEMA } \\
5 \% \text { glutaraldehyde } \\
\text { distilled water }\end{array}$ & $\begin{array}{l}\text { Heraeus Kulzer South America Ltda. } \\
\text { São Paulo, SP, Brazil }\end{array}$ \\
$\begin{array}{l}\text { Amorphous calcium } \\
\text { phosphate }(\mathrm{CP})\end{array}$ & $\begin{array}{l}1.5 \mathrm{~mol} / \mathrm{l} \mathrm{CaCh} \\
1.0 \mathrm{~mol} / \mathrm{l}\left(\mathrm{K}_{2} \mathrm{HPO}_{4}\right)\end{array}$ & Experimental solution \\
\hline
\end{tabular}

according to the experimental approach proposed by Pashley et al. (11). The smear layer was maintained in quadrant 1, which served as the control for the nonexposed dentin. Quadrant 2 was left untreated to serve as the exposed dentin control. The desensitizing agents were applied to quadrants 3 and 4 .

Three desensitizing agents with different characteristics of reactivity to dentin substrate were selected (Table 1): potassium oxalate-based $\left(\mathrm{Oxa}-\mathrm{Gel}^{\circledR}\right)$, glutaraldehyde-based (Gluma Desensitizer), and phosphate and calcium experimental solutions (12). They were applied to quadrants 3 and 4 of the specimens following the manufacturers' instructions: Oxa-Gel ${ }^{\circledR}(\mathrm{OG})$ - applied passively for 3 min to a slightly wet dentin surface and then rinsed and dried with air blast; Gluma Desensitizer (GD) - applied for $60 \mathrm{~s}$ to slightly dried dentin, followed by continuous air-blast drying until the fluid disappeared and the surface was not shiny; Calcium Phosphate Solution (CP) - solution $1\left(\mathrm{CaCl}_{2}\right)$ was applied actively for $5 \mathrm{~s}$ and kept wet with the solution and left undisturbed for an additional $15 \mathrm{~s}$, totaling $20 \mathrm{~s}$. Solution $2\left(\mathrm{~K}_{2} \mathrm{HPO}_{4}\right)$ was applied to the dentin treated with solution 1 and left undisturbed for $10 \mathrm{~s}$. The treated surface was rinsed $30 \mathrm{~min}$ later to simulate the clinical condition in which the patient must avoid the ingestion of any kind of food or liquid for at least $30 \mathrm{~min}$ after the application of these solutions.

After receiving the desensitizing treatments, quadrant 4 was etched again with $6 \%$ citric acid for 1 min to simulate a challenge of the treated areas to an acidic environment as occurs in the mouth during the ingestion of acidic food. This was done to evaluate the sensitivity of treatments to acid challenges. The surface was then rinsed for $15 \mathrm{~s}$ and dried with slight air blast.

An impression was taken of each disc surface immediately after treatment. The impression material used was ultralight-consistency and low-viscosity addition silicone based on quadrafunctional modified siloxane (Aquasil ULV, Dentsply De Trey, Konstanz, Germany), manipulated according to manufacturer instructions and dispensed in the form of a drop onto a glass slab. Each disc was carefully laid on the silicone with the treated surface in contact with the impression material. Slight pressure was 
performed to accommodate the disc in the impression material. After a setting period of 6 min, each disc was removed from the impression and stored in a moist-free environment for $24 \mathrm{~h}$ at $37^{\circ} \mathrm{C}$.

After that time, a low-viscosity epoxy resin (Araltec GY 1109 BR; Ciba Especialidades Químicas Ltda., Guarulhos, SP, Brazil) was mixed following manufacturer instructions and poured into the impression. The specimens were allowed to cure for $24 \mathrm{~h}$ and the replicas were then carefully removed from the impressions. The replicas and the impressions were stored in a moisture-free environment, while the dentin discs were desiccated for $24 \mathrm{~h}$.

The dentin discs and their respective impressions and replicas were mounted on metal stubs and sputter-coated with a $30 \mathrm{~nm}$-thick layer of gold (Hummer VII - Hummer II, Alexandria, KY, USA) and observed in the scanning electron microscope (Zeiss DSM 940 A, Jena, Germany) at a magnification of 1000x (10kV - 14mm).

During the SEM analysis of each specimen (dentin discs, impressions and replicas), the images were obtained from the center of each quadrant.

\section{RESULTS}

\section{$O x a-G e{ }^{\circledR}(O G)$}

Figure 1A illustrates a dentin disc from the smear layer-covered OG group with most of the dentinal tubules completely covered by the smear layer, and a few other tubules just partially occluded. The impression presented in Figure 2A gives an inverted image of Figure 1A with its rough surface and short projections (tags) of impression material, which are coincident with the openings of partially exposed tubules. The replica (Figure 3A) obtained from this impression preserves the very same characteristics of the original smear layer on dentin disc.

In the etched specimen, the smear layer was removed and the openings of the tubules were evident (Figure 1B). The resultant impression of this specimen (Figure 2B) dramatically changed the shape of the silicone tags compared with the non-etched surface. The impression material penetrated deeply into the wide opened dentinal tubules (long twisted tags; arrows in Figure 2B) and partially into those not fully opened (short tags). A few short tags in this figure left their remnants in the dentinal tubules during the impression release, as seen in Figure 1B (arrows).

Figure $3 \mathrm{~B}$ is a view of a replica of the etched dentin disc and shows a clean surface and open dentin tubules as seen in the original dentin disc. However, many low-relief defects (arrows) that correspond to twisted silicone tags can be seen scattered on the replica, sometimes joining the closest dentinal tubules. Except for these defects, the character of this specimen is quite similar of that of Figure 1B.

After treating the dentin disc with OG, the tubule openings were partially occluded by crystal precipitation (Figure 1C, black arrows), usually below the surface, an acid typical reaction of potassium oxalate. A few tubules became occluded with remnants of the silicone tags (white arrows). Because of this partial tubule occlusion, most of the silicone tags in the impression were short and erect (Figure 2C), giving a replica (Figure 3C) with fewer defects than those seen in the replica of the etched dentin disc (Figure 3B). As in the OG treated dentinal surface, the replica copied the deposits on the tubule openings (black arrows) and showed the remnants of silicone tags (white arrows).

Re-etching the OG treated dentin disc with $6 \%$ citric acid dissolved part of the crystal deposits in the tubule openings (Figure 1D) and gave this specimen the same details of the untreated surface. Many tubules remained occluded with remnants of impression material (arrows). Here, too, the impression (Figure 2D) showed the long twisted tags as well as short broken tags, as seen in the untreated specimen. However, the epoxy replica in Figure 3D had small tubule openings, a few of them with signs of crystal precipitation (black arrows), while others remained occluded with fragments of impression material (white arrows). The absence of superficial defects indicates that the area shown in this figure did not match the SEM image of the impression (Figure 2D).

\section{Gluma Desensitizer (GD)}

The smear layer and the acid-etched specimens in this group (Figures $4 \mathrm{~A}$ and $4 \mathrm{~B}$, respectively) presented characteristics that corresponded to those from the OG group. Therefore, the impression and replicas (Figures 5A and B, 6A and $\mathrm{B}$ ) reproduced the same features as described above. Generally, in those tubules that allowed deep penetration of impression material, 
defects were created on the surface of the replica when the impression was separated from the dentin. As the silicone tags were in low number in the impression specimen (Figure 5B, arrows), the number of defects in the replica was also low (Figure 6B, arrows).

No significant differences were seen between the specimen from the dentin disc treated with GD (Figure 4B) and the etched specimen from the same disc (Figure 4C), except for the number and size of dentinal tubules available. However, a considerable number of tubules in Figure 4C (arrows) are partially occluded with an amorphous material, that reduced the size of the tubule openings. Despite that, a number of collapsed silicone tags in the specimen showed that the impression material penetrated deeply into some open tubules (Figure 5C, arrows), which resulted in artifacts on the replica (Figure 6C, arrows). This suggests that the GD might act as a surface-tension reducing agent. Except for these artifacts, the replica can be considered a good reproduction of the treated area.

The specimen challenged with $6 \%$ citric acid is represented in Figure 4D. The area recorded in this specimen had larger diameter dentinal tubules than the others, but no other significant changes were seen when compared with Figure 4C. Here also the tubules were partially occluded with the amorphous material, and a few of them were occluded with silicone plugs (Figure 4D, arrows). The impression actually showed short silicone tags, indicating low penetration of the impression material (Figure 5D). This impression resulted in an epoxy replica (Figure 6D) with low tubular details compared with the surface of the dentin specimen. Only the surface of tubule openings was reproduced.

\section{Calcium Phosphate Solution (CP)}

Figures 7 to 9 correspond to calcium phosphate treated specimens. As in the other groups, the SEM images from smear layer and etched dentin specimens showed that the details of superficial dentin can be easily reproduced by the epoxy resin replicas (Figures 7A and B, 8 A and B, 9 A and B). Figures 8A and 9A show that the impression and epoxy replica had respectively copied and reproduced the main details of the dentinal surface. Narrow tubules generated long thin silicone tags on the impression (Figure 8B, arrows) and delicate artifacts on the replica (Figure 9B, arrows).

A thick smear of precipitated amorphous calcium phosphate (ACP) covers most of the surface of the treated quadrant of the dentin disc (Figure 7C). The tubule openings can be barely seen in the same figure. The siloxane impression of the same quadrant showed short projections of impression material that had reproduced the non-occluded tubule openings (Figure $8 \mathrm{C}$ ). Most of the characteristics of the treated surface were reproduced in the epoxy replica (Figure 9C), including the occluded tubules and some residual calcium phosphate precipitates on the dentin specimen.

The layer of ACP was not resistant to the acid challenge (Figure 7D). The dentin surface was free of crystalline material but small particles concentrated below the tubule openings. The shape of the material occluding the tubules was easily distinguished at this magnification. The siloxane impression shows short silicone tags (Figure 8D) and the epoxy replica (Figure 9D) shows small tubule openings and no signs of ACP precipitation.

Figure 1. SEM photomicrographs of the dentin disc (Oxa-Gel ${ }^{\circledR}$ group). Bars $=10 \mu \mathrm{m}$. A: The dentinal tubules are completely covered by the smear layer and the other tubules are partially occluded. B: Dentin disc after acid-etching. The smear layer was removed, displaying the dentin surface and tubule openings. Remnants of the impression material in the dentinal tubules are present (arrows). C: Post-treatment. The tubule openings are partially occluded by crystal precipitation (black arrows) and a few tubules are occluded with remnants of silicone tags (white arrows). D: Dentin disc re-etched. Some of the intratubular deposits in the tubule openings were dissolved. Remnants of the impression material kept the tubules closed (arrows).

Figure 2. SEM photomicrograph of the siloxane impression of the dentin disc (Oxa-Gel ${ }^{\circledR}$ group). Bar $=10 \mu \mathrm{m}$. A: Short projections (tags) of the impression material can be seen. B: Acid-etched dentin disc. Long twisted tags were formed by the impression material which penetrated deeply into the dentinal tubules (arrows). C: Post-treatment. Short and erect tags of silicone are present due to partial tubule occlusion. D: Dentin disc re-etched. Long twisted and short broken tags can be seen.

Figure 3. SEM photomicrograph of the expoxy replica (Oxa-Gel ${ }^{\circledR}$ group). Bars $=10 \mu \mathrm{m}$. A: The same characteristics of the original smear layer on the dentin disc were preserved. B: Dentin disc after acid-etching. A clean surface, open dentin tubules and low-relief artifacts can be seen. C: Post-treatment. The replica copied the deposits on the tubule openings (black arrows) and remnants of silicone tags are present (white arrows). D: Dentin disc re-etched. Small tubule openings and signs of crystal precipitation can be seen (black arrows). Other tubules remained occluded with fragments of silicone (white arrows). 


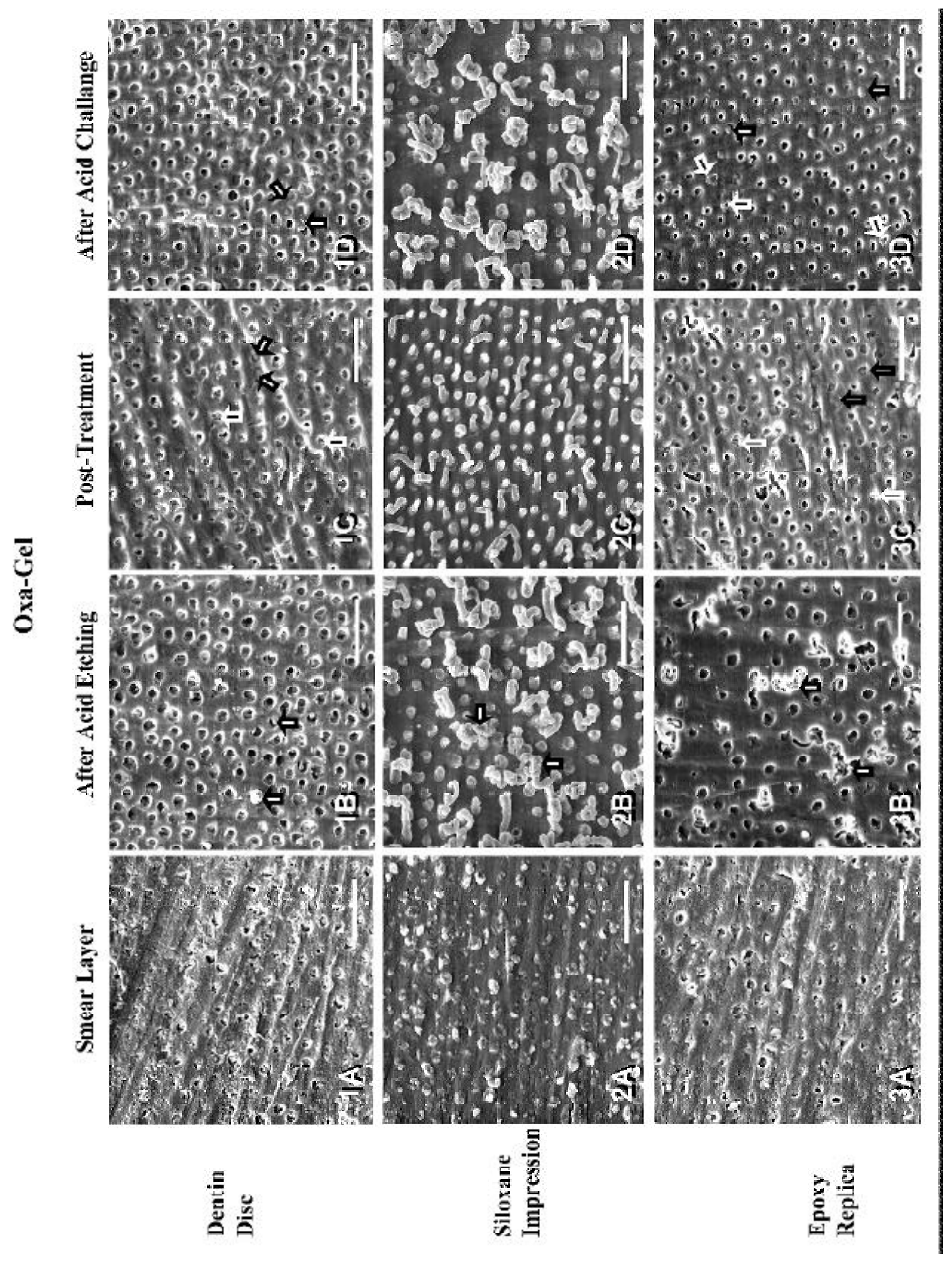


No desensitizing agents/impression material or impression material/epoxy resin chemical reactions that would interfere with the reproducibility of the replica were observed in this investigation.

\section{DISCUSSION}

Three dentin discs were used in this investigation so that several replicas of the different conditions studied could be obtained. The procedure of dividing the dentin discs into four quadrants enabled four different treatment conditions in a single sample, thus reducing the required number of impressions and replicas. Each disc was used as its own control.

An addition cure silicone was used for the dentin discs impressions. Technically, these silicones do not yield by-products while setting, present long-lasting dimensional stability and are compatible with a range of die materials, including epoxy resins. Nevertheless, the manufacturer does recommend at least a one-hour period before pouring epoxy materials, in order to avoid surface porosity of models. Even though Aquasil is an addition cure silicone, based on quadrafunctional modified siloxane, and is therefore, dimensionally and chemically more stable, pouring of epoxy resin was delayed for a minimum period of $24 \mathrm{~h}$. The utilization of ultralight-consistency and low-viscosity addition silicone allows this material to penetrate the dentin tubules, providing a detailed surface impression (Figures 2B, $5 \mathrm{~B}$ and $8 \mathrm{~B})$.

However, these same figures show that when silicone penetration into tubules is deep, their retention strength exceeds their cohesive strength and the resin tags tear off or became deformed during impression.
According to manufacturer instructions, the amount of deformation of Aquasil ULV is about $0.28 \%$, which probably is in the range of deformation formed in the present investigation. This could be one of the shortcomings when employing ultralight-consistency silicone, which may occur regardless of the time lapse before impression removal. In the present work, the impressions were removed from the dentin specimens immediately after setting of the impression material to simulate a clinical condition.

The epoxy replicas were obtained with the use of a low-viscosity liquid epoxy resin, modified with Bisphenyl A-based, a reactive diluent. The liquid hardeners (HY 830 BR and HY 850 BR) utilized were solvent-free, using the correct proportions resulting in a viscous resin that flows into the impression so that all details obtained by the silicone are duly reproduced. Other authors (7) have recommended epoxy resins as an adequate material for replicating details of silicone impressions in the indirect study of dentin surfaces.

Dentin discs are widely employed for the study of dentinal morphology and its interaction with different dental materials. Interesting research methods have been used for the study of dentin hypersensitivity, utilizing devices for measurement of dentin permeability (13) or SEM to evaluate dentin reactivity with desensitizing agents $(7,14)$. Fragments or dentin discs have been frequently used for this purpose, especially when associated with SEM (2). Nevertheless, tooth specimen preparation techniques for SEM may introduce artifacts that make the correct interpretation of the results difficult or even unviable $(8,15)$. In dentinal reactivity tests with desensitizing agents, the laboratory sequences for specimen fixation and dehydration for

Figure 4. SEM photomicrograph of the dentin disc (Gluma Desensitizer group). Bars $=10 \mu \mathrm{m}$. A: Dentinal tubules are completely covered by the smear layer and the other tubules are partially occluded. B: Dentin disc after acid-etching. The smear layer was removed, displaying the dentin surface and tubule openings. C: Post-treatment. Tubule openings are partially occluded by an amorphous material (arrows). D: Dentin disc re-etched. Tubules are partially occluded with amorphous material and a few of them are occluded with silicone plugs (arrows).

Figure 5. SEM photomicrograph of the siloxane impression of the dentin disc (Gluma Desensitizer group). Bars $=10 \mu \mathrm{m}$. A: Short projections (tags) of the impression material can be seen. B: Dentin disc after acid-etching. A small number of silicone tags were formed by the impression material (arrows). C: Post-treatment. The impression material penetrated deeply into some open tubules, forming a few collapsed silicone tags (arrows). D: Re-etched quadrant. Due to the low penetration of the impression material, only short silicone tags can be seen.

Figure 6. SEM photomicrograph of the epoxy replica (Gluma Desensitizer group). Bars $=10 \mu \mathrm{m}$. A: The very same characteristics of the original smear layer on dentin disc were preserved. B: Replica of the dentin disc after acid-etching. A small number of artifacts (arrows) are present. C: Post-treatment. Artifacts (arrows) are shown. D: Dentin disc quadrant treated with Gluma Desensitizer and reetched showing tubular details. 


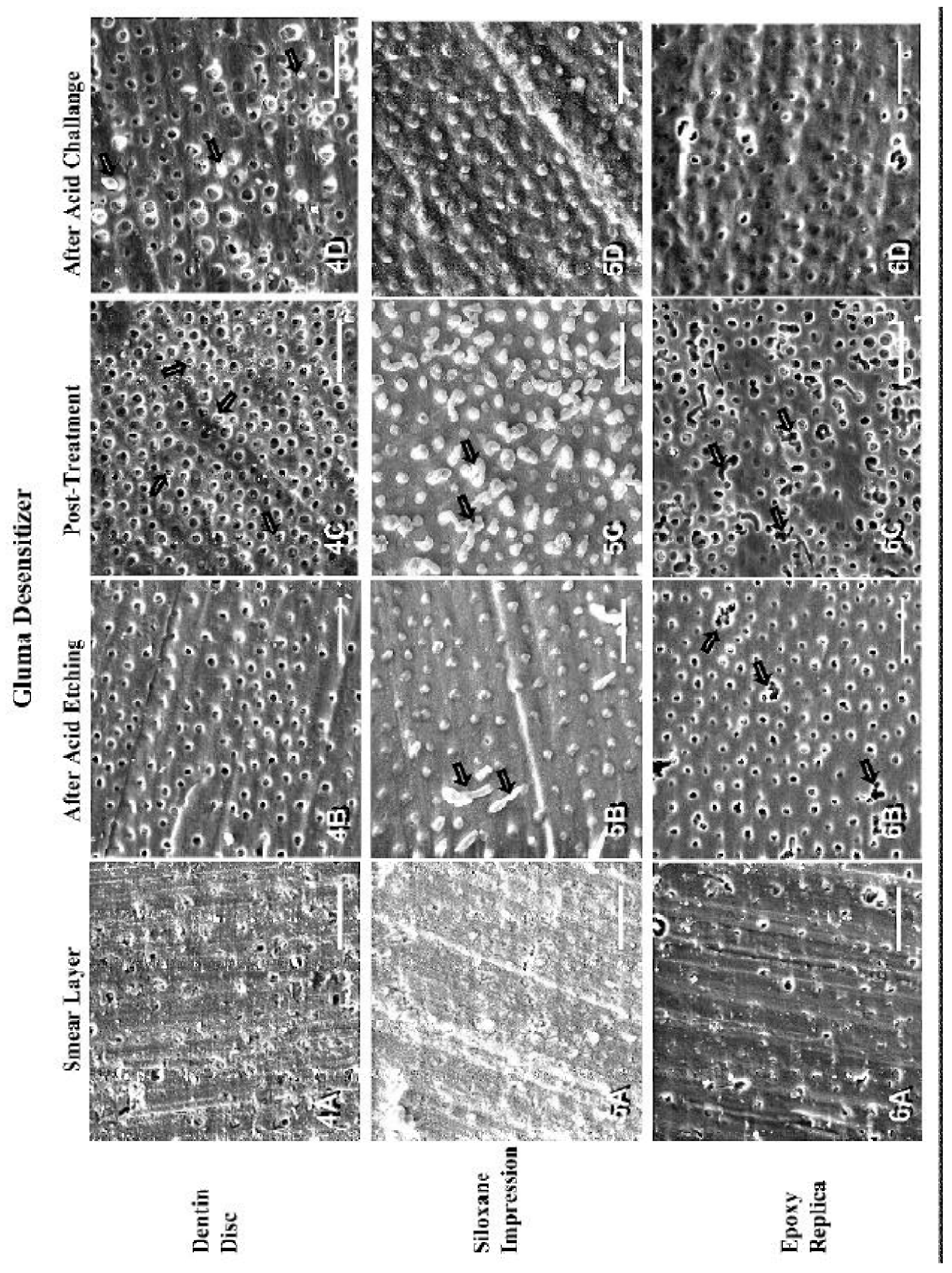

BrazDentJ 13(2) 2002 
further metal-coating, as a rule, result in dissolution of organic and inorganic chemical deposits which accumulate on and in the interior of the dentin tubules. Replication of dentin surface with impression materials and their reproduction in epoxy resin have been used by other researchers, preserving the original specimens and reducing, to some extent, the occurrence of artifacts $(7,10)$. Even in in vivo studies, replicas permit longitudinal evaluations, for it is possible to compare the clinical evolution of treatments and possible changes of dentinal structures $(7,9)$.

The present in vitro investigation aimed at sequential evaluation of dentinal surfaces treated and not treated with the desensitizing agents, and comparing their characteristics with those of corresponding impressions and replicas. This strategy allowed the observation of not only the interaction of desensitizing agents with the dentin, but also their possible interference with impression and replica materials.

The comparison between dentin discs and epoxy surfaces covered with smear layer and of citric acidetched surfaces established the degree of resolution of the impressions and replicas (Figures $3 \mathrm{~A}$ and $\mathrm{B}, 6 \mathrm{~A}$ and B, 9A and B). The typical surface details of the smear layer were easily copied by silicone and duly reproduced by the low-viscosity epoxy resin. However, when the dentinal tubules were exposed and enlarged by acid etching, deep penetration of silicone resulted in the formation of excessively long tags which, upon separation, suffered plastic deformation, becoming twisted and collapsed. The resulting replica incorporated these surface defects, as artifacts, typical of impressions. The wider the dentinal tubules, the more deeply the impression material penetrated and the more easily artifacts were produced. Nevertheless, the acid-etched dentin surface was easily identified. Other authors have also verified the effectiveness of the replica at reproducing dentinal tubules with diameters between 1-2 $\mu \mathrm{m}$ and details as small as of $0.5 \mu \mathrm{m}$, employing silicone impressions (7). This is also in agreement with the technical data of Aquasil ULV, which claim that the material can reproduce details of less than $10 \mu \mathrm{m}$.

In the specimens treated with desensitizing agents that created deposits on or in tubules, the replicas reproduced the characteristics of the treated surface. When OG and CP were used, they reproduced reaction products that deposited crystals slightly below the tubule orifices $(4,14,16)$.

Oxa-Gel $^{\circledR}$, an acidic potassium oxalate-based gel, reacts with the remaining dentin $\mathrm{Ca}^{++}$and generates precipitates of calcium oxalate crystals (14) (Figure 1C). Because the acid etching used to remove the smear layer depletes the calcium phosphate from the dentin surface, the potassium oxalate reacts with the remaining mineral below the surface. Crystal precipitation obstructs the tubule approximately $5 \mu \mathrm{m}$ below the surface (Pereira JC, unpublished observations). This condition limits the depth of penetration of the impression material (Figures $2 \mathrm{~B}$ and $2 \mathrm{C}$ ). The silicone tags are shorter and remain erect in most instances, allowing a replica with fewer artifacts (Figure 3C). In this figure (3C), the presence of subsurface crystalline deposits in the dentinal tubules (arrows) may be seen.

The subsequent challenge of oxalate-treated dentin with citric acid partially dissolved the intratubular crystals, opening up some of the tubules (Figure 1D), which allowed deeper tubular penetration of the impression material (Figure 2D). The remaining crystals gave the tubules a more retentive character, thus causing a certain number of silicone tags to break off and remain in the tubules (Figure 3D, arrows).

The development and improvement of dentinal

Figure 7. SEM photomicrograph of the dentin disc (Calcium Phosphate Solution group). Bars = 10um. A: Dentinal tubules were completely covered by the smear layer. B: Dentin disc after acid-etching. The smear layer was removed, displaying the dentin surface and tubule openings. C: Post-treatment. A thick smear of precipitated ACP covers most of the surface. D: Dentin disc re-etched. The surface is free of particles which concentrated in the tubule openings.

Figure 8. SEM photomicrograph of the siloxane impression of the dentin disc (Calcium Phosphate Solution group). Bars $=10 \mu \mathrm{m}$. A: Short projections (tags) of the impression material can be seen. B: Acid-etched dentin disc. Long thin silicone tags (arrows) can be seen. C: Post-treatment. Short projections of impression material can be seen, above a granular surface texture. D: Re-etched quadrant shows short silicone tags against a smooth surface.

Figure 9. SEM photomicrograph of the epoxy replica (Calcium Phosphate Solution group). Bars $=10 \mu \mathrm{m}$. A: The very same characteristics of the original smear layer on the dentin disc were preserved. B: Epoxy replica after acid-etching shows delicate artifacts (arrows). C: Post-treatment. Replica copied the residues of ACP layer precipitated on the original dentin disc. D: Re-etched quadrant showing small tubule openings. There are no signs of ACP precipitation. 


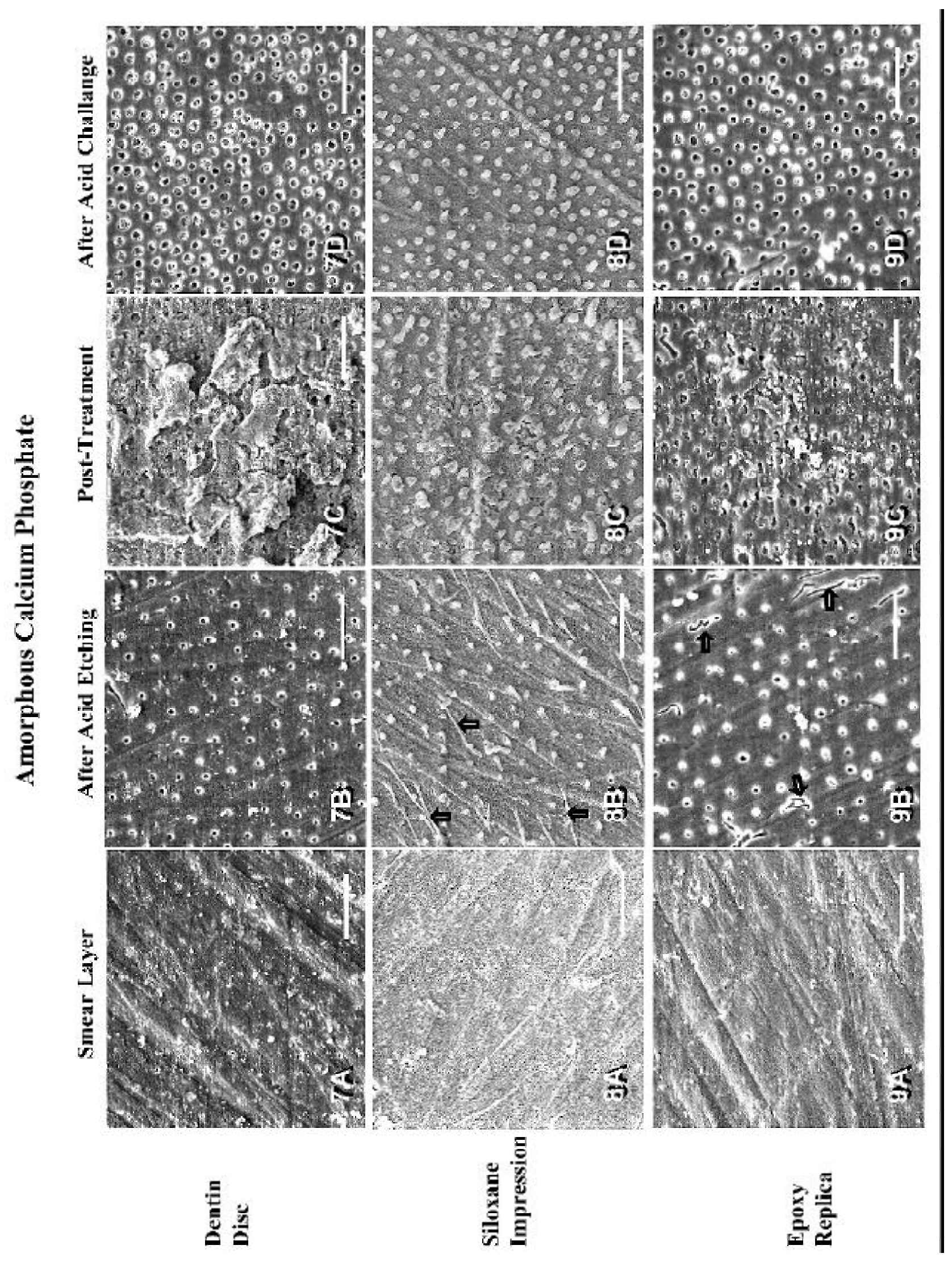

BrazDentJ 13(2) 2002 
adhesives have expanded their applications. Today, they may be used as desensitizing agents. Gluma Desensitizer is a desensitizer which contains 36\% HEMA, $5 \%$ glutaraldehyde and distilled water. As it does not include chemicals to produce polymerization, the desensitizing effect of this agent is thought to occur by precipitation of plasma proteins of dentinal fluid in the interior of the tubules, thereby reducing fluid flow (17). Thus, GD does not produce particle precipitation at the opening or inside the tubules, as OG and CP do. Clinically, GD acts as a primer, creating multiple intratubular septa layers in the lumen of the dentinal tubules as a result of protein precipitation $(18,19)$.

In the present investigation, SEM images of a dentin disc treated with GD frequently showed open dentinal tubules. Some tubules were partially obstructed by delicate septa (Figure 4C, arrow), probably from protein precipitate (19). These features are reproduced by the replica, as can be seen in Figure 6D, which confirms the ability of this procedure to record the main details of the dentinal surface and of the immediate subsurface of the dentinal tubules. However, in this in vitro study, it cannot be expected that the tubule openings have been occluded by protein precipitation, as would occur in vivo. Therefore, small specimen details were changed after acid etching, since the occasional HEMA residue appears to be acid resistant.

$\mathrm{CP}$ treatment involved the sequential use of calcium chloride and potassium phosphate, which produce calcium phosphate precipitates on the dentin and inside the dentinal tubules that have the characteristics of amorphous calcium phosphate (12). As the $\mathrm{pH}$ of the tubule contents decreases and calcium phosphate precipitates lower the ionized calcium concentration, part of the calcium hydroxide, which deposits along with the amorphous calcium phosphate, is dissolved and precipitates as apatite in the presence of phosphate (3). This reaction gives the treated dentin a granular aspect, mainly at the tubule opening (Figures 7C and 7D).

However, in some regions, the surface layer of amorphous calcium phosphate on the dentin surface masked the dentinal tubule orifices (Figure 7C). As a result, the impression also presented a rough surface appearance and some projections of amorphous deposit (Figure 8C). Short silicone projections identify the orifices of dentinal tubules. It seems clear that dentin surface reactions may be reproduced with good precision by the replicas, as observed in Figures 9C and 9D.
The ACP superficial layer was completely removed by the etching, exposing the openings of the obstructed tubules (Figure 7D). These features are reproduced in the epoxy replica (Figure 9D).

The replicas can be an important research tool for monitoring alterations of dentin surface morphology during clinical research on dentin hypersensitivity. The use of impression and replica techniques may allow indirect records of the different reactions between desensitizing agents and the dentinal substrate.

Other authors have stressed the importance of an indirect parallel method in clinical studies on dentin hypersensitivity (7). Oyama and Matsumoto (9) have demonstrated the use of replicas in longitudinal studies of hypersensitive cervical areas, thereby overcoming the difficulty of obtaining clinical samples. The present work demonstrated that important details of dentin surfaces treated with desensitizing agents may be identified in SEM micrographs at the relatively low magnification of 1000x. This non-invasive procedure may be useful in clinical trials in substitution for dentin biopsy (20) or extraction of teeth for direct observation (9).

\section{ACKNOWLEDGMENTS}

The authors would like to thank Nucleo de Apoio a Pesquisa/Microscopia Eletronica Aplicada a Pesquisa Agropecuaria, Escola Superior de Agricultura "Luiz de Queiroz”, Universidade de Sao Paulo, Piracicaba, SP, Brasil, where scanning electron microscopy was performed.

\section{RESUMO}

Pereira JC, Martineli ACBF, Tung MS. Réplica da dentina humana tratada com diferentes agentes dessensibilizantes: estudo in vitro em MEV. Braz Dent J 2002;13(2):75-85.

Este artigo tem como objetivo determinar uma metodologia capaz de reproduzir in vitro a superfície dentinária para observação no MEV, após o uso de diferentes agentes dessensibilizantes. Discos de dentina provenientes de terceiros molares humanos extraídos foram condicionados com ácido cítrico a $6 \%$, foi criada uma smear layer artificial e a superfície dos discos de dentina foi dividida em quatro quadrantes. Os quadrantes 2,3 e 4 de cada disco foram condicionado com ácido cítrico. Os agentes dessensibilizantes (Oxa-Gel ${ }^{\circledR}$, Gluma Desensitizer e um experimental) foram aplicados nos quadrantes 3 e 4 . O quadrante 4 foi novamente condicionado com ácido cítrico a $6 \%$ para avaliar a resistência ao condicionamento. Foi realizada, então, a moldagem 
com Aquasil ULV. Após 6 minutos, cada disco foi removido da moldagem e acondicionado em ambiente livre de umidade por por 24 horas a $37^{\circ} \mathrm{C}$. Decorrido esse período, uma resina epóxica de baixa viscosidade (Araltec GY 1109 BR) foi vazada na moldagem, deixando-a polimerizar por 24 horas. Todos os espécimes foram metalizados para análise no MEV. A comparação das fotomicrografias dos discos de dentina e suas respectivas moldagens e réplicas mostrou que essa técnica pode reproduzir as características da superfície dentinária tratada com os agentes antithiperestésicos.

Unitermos: hipersensibilidade dentinária, réplica.

\section{REFERENCES}

1. Brännström M. Sensitivity of dentin. Oral Surg 1966;21:517526.

2. Gillam DG, Mordan NJ, Newman HN. The dentin disc surface: a plausible model for dentin physiology and dentin sensitivity evaluation. Adv Dent Res 1997;11:487-501.

3. Suge T, Ishikawa K, Kawasaki A, Yoshiyama M, Asaoka K, Ebisu S. Effects of fluoride on the calcium phosphate precipitation method for dentinal tubule occlusion. J Dent Res 1995; 74:1079-1085

4. Tung M, Eichmiller FC, Gibson H, Ly AK, Skrtic D, Schumacher GE. Dentin desensitization by in situ formation of calcium phosphate. J Dent Res 1997;76:387 (abstract).

5. Yeates R, Owens R, Jackson R, Newcombe RG, Addy M. A splitmouth placebo-controlled study to determine the effect of amorphous calcium phosphate in the treatment of dentin hypersensitivity. J Clin Periodontol 1998;25:687-692.

6. Jain P, Vargas MA, Denehy GE, Boyer DB. Dentin desensitizing agents: SEM and $\mathrm{x}$-ray microanalysis assessment. Am J Dent 1997; 10:21-26.

7. Absy EG, Addy M, Adams D. Dentin hypersensitivity: the development and evaluation of a replica technique to study sensitive and non-sensitive cervical dentin. J Clin Periodontol 1989;16:190-195.

8. Bevenius J, Hultenby K. In vitro and in vivo replication for scanning electron microscopy of the cervical region of human teeth. Scanning Microsc 1991;5:731-740.

9. Oyama T, Matsumoto K. A clinical and morphological study of cervical hypersensitivity. J Endod 1991;17:500-502.

10. Rimondini L, Baroni C, Carrassi A. Ultrastructure of hypersensitive and non-sensitive dentine. A study on replica models. J Clin Periodontol 1995;22:899-902.

11. Pashley DH, Kalathoor S, Burnham D. The effects of calcium hydroxide on dentin permeability. J Dent Res 1986;65:417-420.

12. Tung MS, Bowen HJ, Derkson GD, Pashley DH. Effects of calcium phosphate solutions on dentin permeability. J Endod 1993;19:383-387.

13. Pashley DH. Mechanisms of dentin sensitivity. Dent Clin North Am 1990;34:449-473.

14. Pashley DH, Galloway SE. The effects of oxalate treatment on the smear layer of ground surfaces of human dentin. Arch Oral Biol 1985;30:731-737.

15. Fejerskov O, Josephsen K, Nyvad B. Surface ultrastructure of unerupted mature human enamel. Caries Res 1984;18:302-314.

16. Kerns DG, Scheidt MJ, Pashley DH, Horner JA, Strong SL, Van Dyke TE. Dentinal tubule occlusion and root hypersensitivity. J Periodontol 1991;62:421-428.

17. Davidson D, Suzuki M. The Gluma bonding system: A clinical evaluation of its various components for the treatment of hypersensitivity root dentin. J Can Dent Assoc Res 1997; 63:38-41.

18. Dondi dall'orologio G, Lorenzi R, Anselmi M, Opisso V. Dentin desensitizing effects of Gluma Alternate, Health-Dent Desensitizer and Scotchbond Multi-Purpose. Am J Dent 1999;12:103106.

19. Schüpbach P, Lutz F, Finger WJ. Closing of dentinal tubules by Gluma desensitizer. Eur J Oral Sci, 1997;105:414-421.

20. Yoshiyama M, Masada J, Uchida A, Ishida H. Scanning electron microscopic characterization of sensitive vs. insensitive human radicular dentin. J Dent Res, 1989;68:1498-1502. 